\title{
ALIMENTACION INFANTIL EN EL CONSULTORIO EXTERNO
}

\author{
Por el Dr, ERNESTO FIGUEROA R. \\ Jefe del Consultorio Extemo del Hospital Luis Calvo Mackenna.
}

Es este uno de los problemas de mayor importancia y a la vez de más difícil solución que se plantea a la Policlínica de Medicina de un Hospital de Niños.

En esta oportunidad nos referiremos exclusivamente a la alimentación del lactante y pre-escolar, sanos, atendidos por este servicio.

Si existe el propósito de dar una correcta y eficiente atención, es preciso tener presente variados factores al prescribir la dietética a un niño de estas edades. Hay razones dependientes, no sólo de la edad del niño ni de las peculiaridades del metabolismo propias de dicha edad, sino otras que, también, deben ser tomadas muy en consideración por el médico pediatra a cargo de un Servicio Asistencial. Tales factores son los siguientes:

a) Indigencia de los hogares de los niños atendidos.

b) Escasa cultura de los padres y familiares.

$$
\begin{aligned}
& \text { d) Disponibilidades económicas nacio- } \\
& \text { nales. } \\
& \text { Analicemos someramente cada uno de } \\
& \text { ellos, a fin de demostrar su importan- } \\
& \text { cia. }
\end{aligned}
$$
cial.

c) Presupuesto del Servicio Asisten-

\section{a) Indigencia de los hogares de los niños atendidos.}

Es ésta una condición que, por desgracia, la encontramos en casi la totalidad de los niños atendidos por el servicio. El reglamento en uso en nuestro Hospital reserva la atención del Consul- torio Externo única y exclusivamente a Ios indigentes o a niños pertenecientes a hogares con notable escasez de recursos. Ambas circunstancias deben ser comprobadas y controladas periódicamente por el Servicio Social. Actualmente, a los niños inscritos, el Consultorio Externo vende el alimento a precios rebajados o lo proporciona gratuitamente de acuerdo con los Informes de las Visitadoras Sociales.

\section{b) Escasa cultura de los padres $y$ familiares.}

Las prescripciones dietéticas, para que sean fácilmente comprendidas, deben ser ejemplares en su sencillez y enseñadas prácticamente por personal especializado del servicio, ya sea a continuación de la consulta médica, como también en el propio domicilio del niño, amoldando las indicaciones a las disponibilidades materiales del hogar.

Ei cumplimiento de esta modalidad de trabajo requiere la intervención conjunta del Servicio de Enfermeras Sanitarias y Dietistas. Hemos liberado al médico de las explicaciones de técnica culinaria, no sólo para dejar a su disposición mayor tiempo para el examen clínico y anamnesis del niño, sino, también, porque largos años de experiencia en las Policlínicas de Medicina, nos han ensenado que son surnamente frecuentes los casos en que el médico, a pesar de conocer a fondo las Indicaciones clínicas de un determinado alimento, basadas en su composición química, ignore los deta- 
lies de técnica culinaria necesarios para su correcta confección.

Simuitáneamente a la donación o venta a precio mínimo, a veces simbólicn, de los alimentos, surge la necesidad del control y vigilancia de la Enfermera Sanitaria, ejercida en el hogar mismo del niño y destinada a obtener el correcto $\mathrm{y}$ adecuado aprovechamiento de dicho alimento.

Si bien es verdad que la organización de Policlínica que preconizamos hace necesario dotar a estos Servicios de suficiente numero de Visitadoras Sociales, de Enfermeras Sanitarias y Dietistas, los beneficios que hemos obtenido, creemos que compensan con creces este mayor gasto.

\section{c) Presupuesto del Servicio Asistencial.}

En la Beneficencia Pública, en los presupuestos de gastos de los Hospitales de Niños, todavía no se consulta, sistemáticamente, un rubro destinado a la adquisición de alimentos para los niños atendidos por el Consultorio Externo, de donde las frecuentes crisis en su regular aprovisionamiento. Esta omisión crea un notable tropiezo y profundá desorganización de la labor médico-social de cstos servicios. Creemos que, jerarquizanco las necesidades de un Hospital de Niños, modernamente organizado, el rubro "Alimentación de los niños asistidos por la Policlínica de Medicina" debe ser tuno de los primeros, atendiendo a su importancia médico-social.

El-hambre, la insuficiente alimentación durante la edad infantil, tienen grave y honda repercusión sobre la porción más delicada, sensible y vulnerable de nuestra nacionalidad.

\section{d) Disponibilidades económicas nacionales.}

Al prescribir un alimento, el Pediatra ha de tomar, también, en consideración su existencia regular y suficiente en el mercado.

Una de las características de nuestra economia nacional no es tan sólo el elevado costo de la alimentación infantil, sino, también, los largos y frecuentes periodos en que desaparecen totalmente del comercio alimentos básicos, tales como la leche y el azúcar. Estas desapariciones preceden, a veces, en meses a las alzas que constantemente experimentan dichos artículos. Las causas de estas crisis económico-sociales están fuera de la órbita de nuestra acción de médicos y preferimos no pronunciarnos sobre ella, pero no podemos, en conciencia, liberarnos de la obligación de dejar constancia, desde esta tribuna, de la grave y funesta repercusión que tienen sobre los niños de nuestra patria.

Su solución sería posible, si se abordara el estudio de estos problemas, no con criterio restringido, sino nacional. Para ello es indispensable la estrecha cooperación del técnico en Economía Social, el técnico en Nutrición y los Médi$\cos$ Pediatras. Mas, ante todo, es necesario proceder a uniformar el criterio de los médicos respecto a la alimentación Infantil. Por ejemplo, los médicos prescriben la leche bajo múltiples formas diferentes. Unos son partidarios de la leche fresca, recién ordeñada (leche de establo), otros de la leche pasterizada. La leche condensada tiene también sus leales y arđoorosos defensores. Con no menos adeptos cuenta la leche desecada. Estos se dividen entre aquellos que la preconizan natural y partidarios de la acídíficada. La presencia o ausencia de crema constituyen una causal más para una nueva división de opiniones. Igual cosa sucede con las harinas para niños.

La actual divergencia de opiniones ha traído como consecuencia una desorientación de la oninión pública $\mathrm{y}$ ha permitido la aparición y existencia en el mercado de alimentos cuyas complicadas y abigarradas fórmulas revelan bien a las claras su origen neta y exclusivamente comercial. Su exagerado número, unido a la falta de personal técnico, de laboratorios y de comodidades materiales, hacen imposible al Departamento Nacional de Alimentación de la 
Valor comercial de $10 \mathrm{~g}$ de Proteinas obtenidas de:

Carne: $100 \mathrm{~g}=20 \mathrm{~g} \mathrm{P}$.

60 g cazuela a precio comisariato

60 g cazuela a precio real de venta

$60 \mathrm{~g}$ cazuela término medio

50 g lomo a precio comisariato

$50 \mathrm{~g}$ lomo a precio real de venta

$50 \mathrm{~g}$ lomo a precio término medio

$50 \mathrm{~g}$ filete a precio comisariato

$50 \mathrm{~g}$ filete a precio real de venta

$50 \mathrm{~g}$ filete término medio

$\begin{array}{lll}\$ 1.68 & \mathrm{~kg} & \mathbf{2 8 . -} \\ 2.64 & " 1 & 44 .- \\ 1.92 & " & 36 .- \\ 2.40 & " & 48 .- \\ 2.30 & " & 60 .- \\ 2.60 & " & 52 .- \\ 3 .- & " & 60 .- \\ 4,30 & " & 86 .- \\ 3.70 & " & 79-\end{array}$

Leche: $100 \mathrm{~g}=3.5 \mathrm{P}$.
300 i leche a precio comisariato

300 g leche a precio establo

$300 \mathrm{~g}$ leche término medio $\begin{array}{lll}1.92 & \text { lt } & 6.40 \\ 2.40 & " & 8 .- \\ 2.10 & " & 7.20\end{array}$

Pescado, merluza: $100 \mathrm{~g}=17 \mathrm{~g}$.

$60 \mathrm{~g}$ pescado a precio comisariato

60 g pescado a precio real de venta

$60 \mathrm{~g}$ pescado término medio

Porotos: $100 \mathrm{~g}=20 \mathrm{~g} \mathrm{P}$.

$50 \mathrm{~g}$ porotos a precio comisariato

\$0 $\mathrm{g}$ porotos a precio real de venta

$50 \mathrm{~g}$ porotos término medio

$\begin{array}{lll}0.68 & \Rightarrow & 13.60 \\ 1 .- & \Rightarrow & 20 . . \\ 0.84 & \quad & 16.80\end{array}$

Valor comercial de 100 calorias obtenidas de:

Carne: $100 \mathrm{~g}=155$ calorias.

BO g cazuela a preclo comisariato

80 g cazuela a preclo real te venta

$80 \mathrm{~g}$ cazuela término medio

60 g lomo a precio comisariato

$60 \mathrm{~g}$ lomo a precio real de venta

$60 \mathrm{~g}$ lomo término medio

$60 \mathrm{~g}$ filete a precio comisariato

$60 \mathrm{~g}$ filete a precio real de venta

$60 \mathrm{~g}$ filete término medto

$\begin{array}{ccc}\$ 2.24 & \text { kg } & \$ 28 .- \\ 3.50 & " & 44- \\ 2.60 & " & 32 .- \\ 2.88 & " & 48 .- \\ 3.36 & " & 60 .- \\ 3.12 & " & 52 .- \\ 3.60 & " & 60 .- \\ 5.16 & " & 36 .- \\ 4.38 & " & 73-\end{array}$

Porotos: $100 \mathrm{~g}=322$ calorias.

31 g porotos a precio comisariato

$31 \mathrm{~g}$ porotos a precio real de venta

$0.42 \quad " \quad 13.60$

$81 \mathrm{~g}$ porotos término medio

$0.62 \quad " \quad 20$.-

$0.52 \quad " 16.80$

Pan: $100 \mathrm{~g}=255$ calorias.

$39 \mathrm{~g}$ pan a precio comisariato

$\begin{array}{lll}0.37 & \prime & 9.80 \\ 0.47 & \prime & 12 .- \\ 0.42 & \quad & 10.80\end{array}$

$39 \mathrm{~g}$ pan término medio

Leche: $100 \mathrm{~g}=60$ calorias.

$166 \mathrm{~g}$ leche a precio comisariato

$166 \mathrm{~g}$ leche termino medio 
Dirección General de Sanidad, mantener el indispensable control bromatológico sobre ellos, tanto más necesario, cuanto que están destinados a la población infantil. Esta imposibilidad de control es seguramente conocida por los fabricantes, pues, como dato interesante referiremos que hace ya tiempo, hemos observado en el Hospital frecuentes casos de trastornos nutritivos agudos, acompañados de síntomas típicos de gastritis. La anamnesis de estos niños da a conocer, con suma frecuencia, que son alimentados con uno de los preparados comerciales más voceados por la radio y cuyo nombre figura constantemente en letras de molde en los avisos de la pren'sa. Lo más verosímil es atribuir la causa de estos trastornos a la presencia de sustancias indigestas $\mathrm{y}$ de mala calidad. La falta de una acción enérgica, conjunta y disciplinada de los médicos Pediatras, desautorizando y combatiendo el uso sistemático de estos alimentos, ha hecho posible su existencia y la fama de que gozan.

Mencionamos la leche obtenida en los establos situados en las ciudades. Estos negocios existen gracias al prestigio de que goza, para algunos médicos, la leche fresca y recién ordeñada. Las mismas razones antes mencionadas, hacen imposible a la Dirección General de Sanidad, controlar la constante higiene de la leche, la salud del ganado, ni la honradez del propietario, para no aumentar, a espaldas del funcionario sanitario, el producto de la ordeña, mediante el agregado de leche de otras procedencias o el residuo de ordeñas anteriores, conservadas sin ninguna higiene ni refrigeración.

En presencia de estos hechos creemos que corresponde a la Sociedad Chilena de Pediatría abordar el problema de uniformar el criterio médico sobre la alimentación infantil, de acuerdo con Sociedades Científicas que agmupan a los técnicos en Nutrición y así, unidos, podamos solicitar de los organismos técnicos estatales el fomento de la producción de determinados alimentos y la prohibición de la fabricación de otros.
Planteado así, a grandes rasgos, el problema de la alimentación infantil en el Consultorio Externo, daremos a conocer someramente la conducta seguida en la Políclínica de Medicina del Hospital Luis Caivo Maćkenna.

Los informes del Servicio Social, peribdicamente renovados, han seleccionado a 400 niños menores de 2 años, a quienes es preciso racionar con alimentos suministrados gratuitamente por el Hospital. La ración máxima donada en cada caso es un número de gramos de leche, completa, desecada, equivalente a medio litro de leche de vaca fresca. Esta cuota es entregada semanalmente por la Farmacia del servicio, previa receta otorgada por el médico de la sección "Niños Sanos". En la "tarjeta de alimentación" queda constancia de la fecha de entrega del alimento y el número de días que debe durar. Hemos preferido la leche desecada por su resistencia a las contaminaciones exógenas, escaso volumen y peso, lo cual facilita grandemente su transporte $\mathrm{y}$ al hecho de poder entregarse a los familiares empaquetada, siempre en un envase distinto al original, lo cual dificulta su venta a personas que ignoran su procedencia. El regular ascenso ponderal, en ausencia de toda afección intercurrente, nos indica el cumplimiento de las indicaciones médicas y el empleo del alimento en la forma prescrita por el Servicio. En caso contrario se solicita a la Enfermera Sanitaria que visite el hogar y constate el destino y uso del alimento. El informe desfavorable de estos funcionarios a la reiterada inasistencia a citaciones de control, son causales suficientes para la suspensión de este beneficio.

Bien comprendemos que las raciones indicadas son apenas suficientes para la alimentación de un lactante sano $y$ que debíamos extender los beneficios al niño pre-escolar, edad de la vida al margen de toda labor asistencial. Desgraciadamente, la escasez de recursos nos obliga a restringir y mutilar nuestra labor médico-soctal. 
A pesar de nuestros esfuerzos, razones materiales, tales como falta de espacio para la instalación de una amplia y cómoda cocina y la carencia de suficiente número de dietistas, nos han impedido dar a esta sección el auge necesario y enseñar a las madres la manera científica y racional de alimentar al niño. Hoy tan sólo nos limitamos a la enseñanza práctica de la alimentación del lactante. Conjuntamente con esta labor tratamos de implantar una despensa y en la cual se expendería a precios de costo determinados alimentos. Esta sección no sería un vulgar "almacén de comestibles", si no un laboratorio de experimentación y un centro de difusión de nuevas fórmulas de alimentación, preconizadas por los técnicos en Nutrición $\mathrm{y}$ Economia Social. Entre estos alimentos figurarían, tal vez: harinas de leguminosas, pescado deshidratado, leches des-. cremadas desecadas, albúminas provenientes de levaduras, etc., etc. En una palabra, todos aquellos alimentos que, por su facilidad de confección, sus caracteres de alimento completo y su bajo costo, aliviarian la trágica situación de las clases indigentes $y$ pondría al niño a cubierto de los perjuicios de una alimentación carenciada y el Hospital habría cumplido así una finalidad más de su misión médico-social.

\section{Resumen.}

La alimentación infantil, en un servicio asistencial, que controla grandes masas de individuos, ha de ser orientada y dirigida, no con un criterio restringido $\mathrm{y}$ local, sino que ha de atenderse, conjuntamente con las peculiaridades del metabolismo del niño, a las disponibilidades nacionales. Es preciso una estrecha cooperación de los técnicos en Economía Social, Nutrición, Sanidad y médicos pediatras.

\section{Summary.}

Infantile feeding in a welfare service, that controls many children, must be guided not with a local and restricted criteria, but must consider besides the peculiarities of metabolism in children the national characteristics. To achieve this the pediatritian must work in close colaboration with experts on social economy, nutrition and public health. 